\title{
Publisher Correction: Carbon nanotubes as emerging quantum-light sources
}

X. He (1) , H. Htoon (1), S. K. Doorn (1), W. H. P. Pernice (1), F. Pyatkov (D), R. Krupke, A. Jeantet, Y. Chassagneux (1) and C. Voisin (1)

Correction to: Nature Materials https://doi.org/10.1038/s41563-018-0109-2, published online 18 June 2018.

In the version of this Perspective originally published, the $x$-axis label of Fig. $1 \mathrm{~d}$ was missing; it should have read 'Wavelength (nm)'. The citations to Fig. $1 \mathrm{~g}$ and Fig. $1 \mathrm{~h}$ in the main text were incorrect; they should have been to Fig. 1f and Fig. 1g, respectively. The units of the $y$ axis of Fig. 2c were missing; they should have read nm. The values under the $x$-axis tick marks for Fig. 2e were missing, they should have read 1,355, 1,370 and 1,385. The units of the $y$ axis of Fig. $3 \mathrm{~b}$ were incorrect; they should have been meV. The first citation to Fig. 3b in the main text was incorrect; it should have been to Fig. 3a. The citation of Fig. $3 \mathrm{c}$ in the main text was incorrect; it should have been to Fig. 3b. And the two instances in the 'Outlook' section of the units $\mathrm{eV}$ were incorrect; they should have been $\mu \mathrm{eV}$. These issues have now been corrected.

Published online: 11 July 2018

https://doi.org/10.1038/s41563-018-0141-2 